\title{
Morphological and morphometric analysis of the shape, position, number and size of mental foramen on human mandibles
}

\author{
Alma Voljevica*, Elvira Talović, Aida Hasanović \\ Institute of Anatomy "Prof. dr. Hajrudin \\ Hadžiselimović” Faculty of Medicine \\ University of Sarajevo, Sarajevo, Bosnia \\ and Herzegovina

\footnotetext{
*Corresponding author: alma.voljevica@yahoo.com Tel.: + 38733665 949/143

Fax.: + 38733203670
} \\ Received: 2 October 2014 \\ Accepted: 25 February 2015 \\ Key words: Mental foramen - Accessory \\ mental foramen - Mandible - Premolar \\ tooth

\begin{abstract}
Objective. To provide anatomical information on the position, morphological variations and incidence of mental foramen (MF) and accessory mental foramen (AMF) as they are important for dental surgeons, anesthetists in nerve block and surgical procedures, to avoid injury to the neurovascular bundle in the mental foramen area. Methods. Our study was conducted on 150 adult dry human mandibles from the osteological collection of the Department of Anatomy of the Faculty of Medicine, University of Sarajevo. The location and shape of the MF and the presence of the AMF were studied by visual examination. The size and position of the MF were measured using a digital vernier caliper. SPSS, version 17 software was used for the statistical analysis. Results. Bilateral mental foramina were presented in all 150 mandibles. In the majority of mandibles, the MF was located between the first and second premolar $(20.3 \%)$ or on the level of the root of the second premolar $(60.3 \%)$, midway between the inferior margin and the alveolar margin of the mandible. Most of the mental foramina were oval in shape (83.3\%). An AMF was present in four mandibles $(2.7 \%)$ on the right side. Conclusion. This study may be a very useful new supplement to data on variations in the incidence, position, shape and size of mental and accessory mental foramina, which may help surgeons, anaesthetists, neurosurgeons and dentists in carrying out surgical procedures successfully.
\end{abstract}

\section{Introduction}

The mental foramen (MF) is a small foramen situated in the anterolateral aspect of the body of the mandible. Normally, the MF is located below the interval between the premolars. It transmits the mental nerve, an artery and a vein. The mental nerve is a branch of the inferior alveolar nerve which supplies sensation to the lower lip and the labial mucosa and lower canines and premolars. Variations in the position of the
MF have been reported by many authors in different ethnic groups $(1,2)$ and various shapes have also been noticed (3). Any foramen in addition to the MF in the body of the mandible is known as an accessory mental foramen (AMF). The AMF transmits the accessory branch of the mental nerve.

Precise knowledge on variations in the position, shape, and the size of the MF and the presence of the AMF would be of great use for dental surgeons while performing surgical procedures on the mandible, such as curet- 
tage of premolars, filling procedures, dental implants, root canal treatments, orthognatic surgeries, etc. It is also essential to have effective and a successful anesthesia during nerve blocks, prior to surgical procedures (4).

Many studies have been reported by various authors, which were carried out on different ethnic groups and on populations of different races, but such studies reported in the Bosnian population are sparse. Hence, an attempt was made in our present study to determine the most common position and size of the MF in adult Bosnian mandibles, which may be useful for future implications in our Bosnian population.

\section{Methods}

The mandibles used for our study were procured from the Department of Anatomy, Faculty of Medicine, University of Sarajevo. 150 adult dry mandibles, irrespective of age and sex, with either all the teeth intact or with preserved alveolar margins, were used for our study. The number, shape and the positions of the MF were determined by a visual examination. The positions of the MFs were measured with respect to the teeth, for which we followed the Tebo and Telford classification (5): I=The MF is projected between the canine and first premolar; II=The MF is projected at the level of the first premolar; III=The MF is projected between the first and second premolars; $\mathrm{IV}=$ The MF is projected at the level of the second premolar; $\mathrm{V}=$ The $\mathrm{MF}$ is located in between the second premolar and first molar; VI=The MF is located at the level of the first molar (Figure 1).

\section{Morphometric analysis}

We measured the distance of the MF (in $\mathrm{mm}$ ) from various landmarks, including the

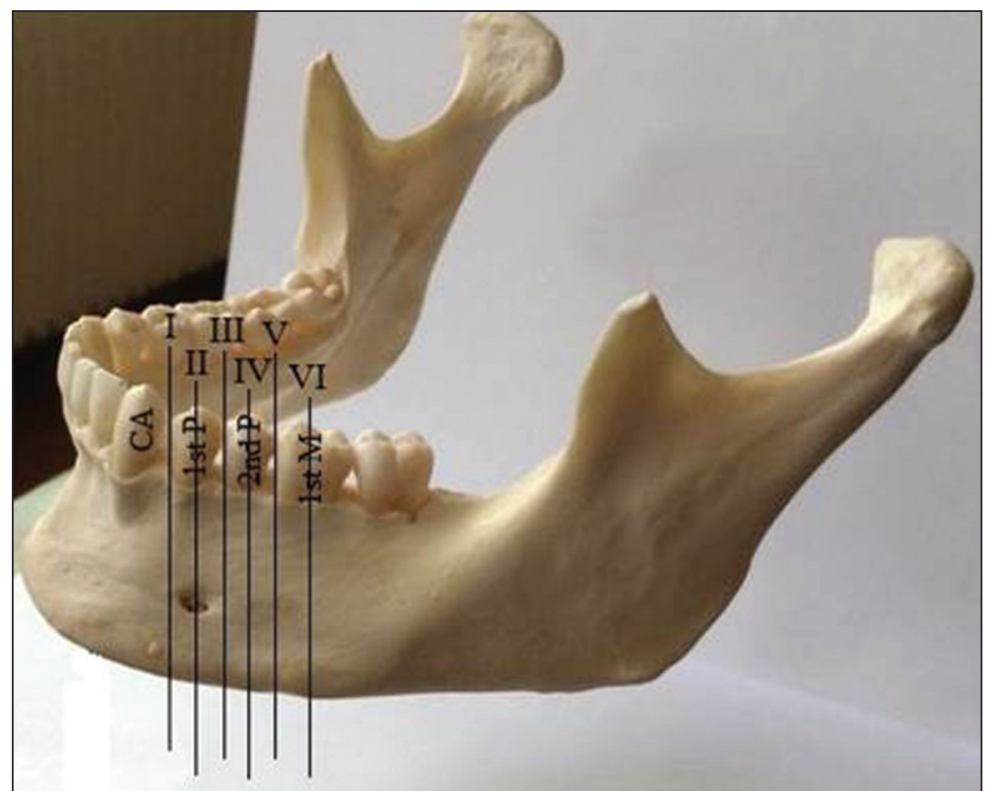

Figure 1 Location of the mental foramen compared to the teeth (I-VI):

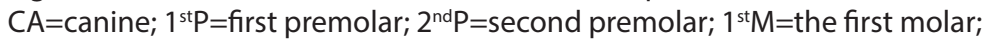
$\mathrm{I}=$ The MF is projected between the canine and first premolar; II=The MF is projected at the level of the first premolar; III=The MF is projected between the first and second premolars; IV=The MF is projected at the level of the second premolar; $\mathrm{V}=$ The MF is located in between the second premolar and first molar; $\mathrm{VI}=$ The MF is located at the level of the first molar. 


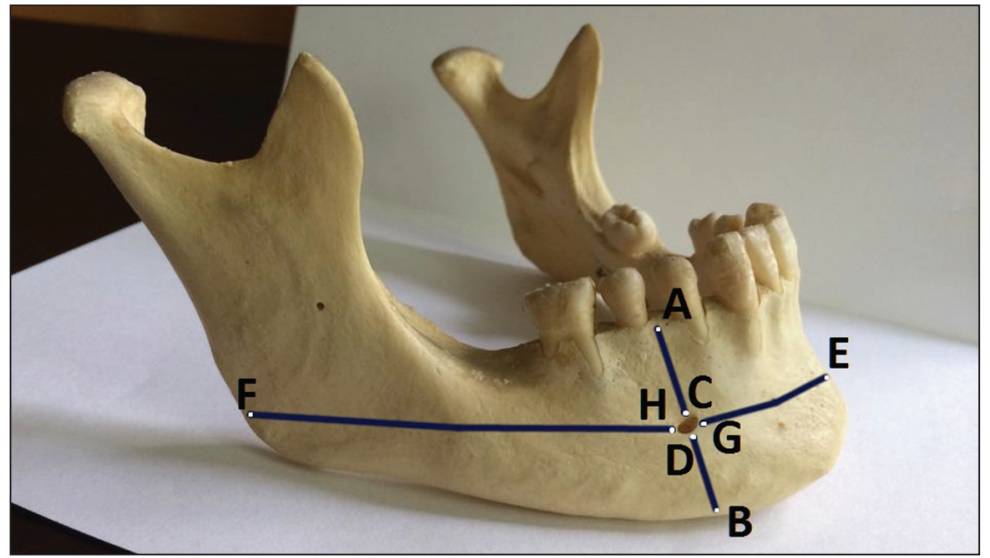

Figure 2 Position of the MF and its size calculated by transverse and vertical measurements of the mandible in relation to borders $A B$ : The distance from the bottom edge of the mandible body to the processus alveolaris; AC: The distance from the processus alveolaris to the upper edge of the foramen mental; $\mathrm{BD}$ : The distance from the bottom edge of the mandible body to the bottom edge of the MF; $C D$ : The height or vertical diameter of the MF $[A B-(A C+B D)] ; E F:$ The distance from the mental symphisis to the back edge of the ramus mandibulae; EG: The distance from the mental symphisis to the front edge of the MF; FH: The distance from the back edge of the ramus mandibulae to the back edge of the MF; GH: The horizontal width or diameter of the MF [EF-(EG+FH)].

symphysis menti, the alveolar crest, the posterior border of the ramus of the mandible, and the lower border of mandible, with digital vernier calipers, and calculated the size of the MF. The measurement of all parameters was performed on both sides (Figure 2).

\section{Statistical analysis}

Data were analyzed using SPSS version 17. The location and size of the MF were determined by the minimum and maximum values, mean and standard deviation. Testing differences in the position and dimensions of the MF between men and women was performed using the Mann-Whitney test. The chi-square method was used to examine the difference in the location of the MF compared to the teeth on the left and right sides. We also analyzed differences in those parameters between males and females. All statistical results where $\mathrm{p}<0.05$ were considered statistically significant.

\section{Results}

\section{The Mental foramen}

In our present study, 150 bones (100\%) showed a single MF on the left side and 147 (97.3\%) showed a single foramen on the right side. The most common position of the MF on the examined mandibles on the right side was on the longitudinal axis of the second premolar (position IV), followed by positions III, II, V. No MF was observed in positions I and VI in any mandible. The most common position of the MF on the examined mandibles on the left side was on the longitudinal axis between the first and second premolars (position III), followed by positions IV, II, V and VI. No MF was observed in position I in any mandible. A statistically significant difference was found in the location of the MF compared to the teeth on the right and left sides using chi-square test $\mathrm{p}<0.05$. 
Table 1 The difference in mental foramen (MF) location compared to the teeth and interalveolar septum on the right side between the genders

\begin{tabular}{llllllll}
\hline \multirow{2}{*}{ Gender } & \multicolumn{2}{l}{ Position (right side) } & & & \\
\cline { 2 - 7 } & I & II & III & IV & V & VI & Total \\
\hline Male & - & 4 & 21 & 63 & 9 & 0 & 97 \\
Female & - & 2 & 9 & 29 & 13 & 0 & 53 \\
Total & - & 6 & 30 & 92 & 22 & 0 & 150 \\
\hline
\end{tabular}

$\mathrm{I}=$ The MF is projected between the canine and first premolar; II=The MF is projected at the level of the first premolar; III=The MF is projected between the first and second premolars; IV=The MF is projected at the level of the second premolar; $V=T h e$ MF is located in between the second premolar and first molar; $\mathrm{VI}=$ The MF is located at the level of the first molar.

Table 2 The difference in mental foramen (MF) location compared to the teeth and interalveolar septum on the left side between the genders

\begin{tabular}{llllllll}
\multirow{2}{*}{ Gender } & \multicolumn{2}{l}{ Position (left side) } & & & & \\
\cline { 2 - 7 } & I & II & III & IV & V & VI & Total \\
\hline Male & - & 2 & 24 & 59 & 9 & 3 & 97 \\
Female & 0 & 2 & 7 & 30 & 14 & 0 & 53 \\
Total & 0 & 4 & 31 & 89 & 23 & 3 & 150 \\
\hline
\end{tabular}

$\mathrm{I}=$ The MF is projected between the canine and first premolar; $\|=T$ The MF is projected at the level of the first premolar; III=The MF is projected between the first and second premolars; IV=The MF is projected at the level of the second premolar; $V=T h e$ MF is located in between the second premolar and first molar; $\mathrm{VI}=$ The MF is located at the level of the first molar.

The chi-square test showed that there was no statistically significant difference in MF location regarding the left or right sides, when comparing teeth between men and women. On the right side: $\mathrm{p}=0.994$, and on the left: $p=0.810$. These results are presented in Tables 1 and 2.

With respect to the superior and the inferior borders of the mandible, most of the MF were found to occupy the mid position.

The MF was positioned at an average distance of $14.37 \pm 4.22 \mathrm{~mm}$ from the alveolar margin on the left side, whereas it was positioned at a distance of $14.37 \pm 4.37$ $\mathrm{mm}$ on the right side. From the symphysis menti, the MF was located at a distance of about $25.65 \pm 2.11 \mathrm{~mm}$ on the left side and at a distance of about $25.61 \pm 1.93 \mathrm{~mm}$ on the right side. The average distance of the MF from the posterior border of the mandible was $58.68 \pm 4.70 \mathrm{~mm}$ on the left side and $59.34 \pm 4.50 \mathrm{~mm}$ on the right side. From the base of the mandible, it was located at a dis- tance of $12.72 \pm 1.66 \mathrm{~mm}$ on the left side and at a distance of $12.67 \pm 2.00 \mathrm{~mm}$ on the right side. The mean vertical diameter of the MF in our study was $1.71 \mathrm{~mm} \pm 1.02 \mathrm{~mm}$ on the right side and $1.69 \mathrm{~mm} \pm 0.64 \mathrm{~mm}$ on the left side, respectively, and the mean horizontal diameter was $2.56 \mathrm{~mm} \pm 1.05 \mathrm{~mm}$ on the right side and $2.41 \mathrm{~mm} \pm 0.94 \mathrm{~mm}$ on the left side (Table 3 ).

\section{Shape}

In 150 bones, (83.3\%) the MF bilaterally showed an oval shape and in the remaining 25 mandibles (16.7\%) the MF bilaterally showed a round shape.

\section{The Accessory mental foramen}

Among the researched material there were 4 cases, or $2.7 \%$, in which the existence of an AMF was reported, and its location in all four cases was on the right side (Figure 3). 
Table 3 Morphometric measurement values

\begin{tabular}{|c|c|c|c|}
\hline Morphometric measurement & Side & $\bar{x} \pm S D$ & Range \\
\hline \multirow{2}{*}{$\begin{array}{l}\text { The distance from the bottom edge of the mandible body to the processus } \\
\text { alveolaris }\end{array}$} & Right & $28.79(5.167)$ & $13-44$ \\
\hline & Left & 28.79 (4.979) & $16-42$ \\
\hline \multirow{2}{*}{$\begin{array}{l}\text { The distance from the processus alveolaris to the upper edge of the foramen } \\
\text { mental }\end{array}$} & Right & $14.37(4.371)$ & $1-24$ \\
\hline & Left & $14.37(4.223)$ & $2-25$ \\
\hline \multirow{2}{*}{$\begin{array}{l}\text { The distance from the bottom edge of the mandible body to the bottom edge } \\
\text { of the MF }\end{array}$} & Right & $12.67(2.008)$ & 2-19 \\
\hline & Left & $12.72(1.665)$ & 8-16 \\
\hline \multirow{2}{*}{ The height or vertical diameter of the MF $[A B-(A C+B D)]$} & Right & $1.71(1.027)$ & $1-11$ \\
\hline & Left & $1.69(0.645)$ & $1-4$ \\
\hline \multirow{2}{*}{$\begin{array}{l}\text { The distance from the mental symphisis to the back edge of the ramus } \\
\text { mandibulae }\end{array}$} & Right & $87.52(4.861)$ & 71-102 \\
\hline & Left & $86.75(4.872)$ & $75-101$ \\
\hline \multirow{2}{*}{$\begin{array}{l}\text { The distance from the mental symphisis to } \\
\text { the front edge of the MF }\end{array}$} & Right & $25.61(1.931)$ & $21-32$ \\
\hline & Left & $25.65(2.115)$ & $20-32$ \\
\hline \multirow{2}{*}{$\begin{array}{l}\text { The distance from the back edge of the ramus mandibulae to the back edge of } \\
\text { the MF }\end{array}$} & Right & $59.34(4.506)$ & $46-71$ \\
\hline & Left & $58.68(4.701)$ & $43-71$ \\
\hline \multirow{2}{*}{ The horizontal width or diameter of the MF $[E F-(E G+F H)]$} & Right & $2.56(1.052)$ & $1-7$ \\
\hline & Left & $2.41(0.943)$ & $1-5$ \\
\hline
\end{tabular}

$M F=$ Mental foramen; $A B=$ The distance from the bottom edge of the mandible body to the processus alveolaris; $A C=$ The distance from the processus alveolaris to the upper edge of the foramen mental; $B D=$ The distance from the bottom edge of the mandible body to the bottom edge of the MF; EF=The distance from the mental symphisis to the back edge of the ramus mandibulae; EG=The distance from the mental symphisis to the front edge of the MF; $\mathrm{FH}=$ The distance from the back edge of the ramus mandibulae to the back edge of the MF.

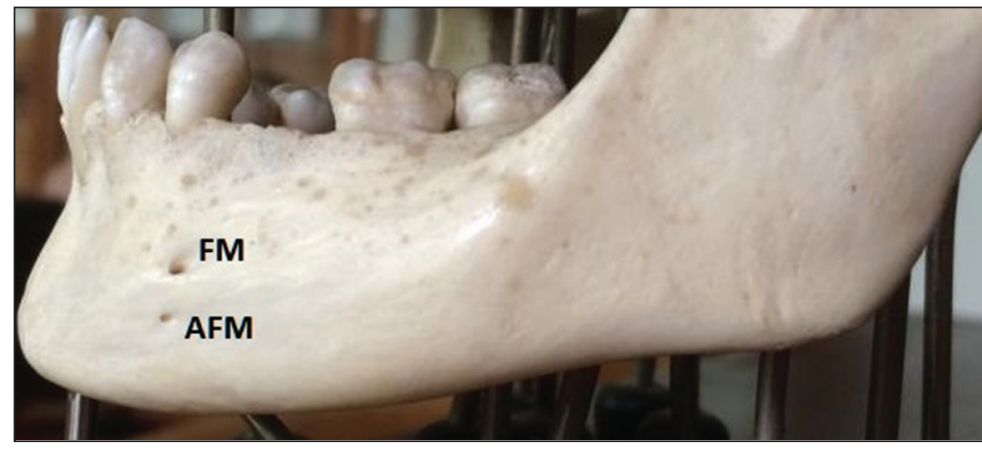

Figure 3 Typical location of the mental foramen in the area of the second premolar; Below the mental foramen an accessory mental foramen is noted.

\section{Discussion}

The location of the MF is an important factor when considering the mental incisive anesthetic block and surgery in the outer premolar mandibular region (6). There are significant differences reported in the location of the MF among different ethnic groups (7). Igbigbi and Lebona (8) in Ma- lawians and Mbajiorgu (9) in Zimbabweans mandibles reported position IV as the most common followed by position V. However, Santini and Land (10) in British and Green (11) in Chinese mandibles observed position III as the most common, followed by position IV. In other studies on Kenyan mandibles (12), position III was found to be most common, followed by position II, and 
in the Malay populations (13) the most common position was IV, followed by III, but in these studies the right and left sides were not considered separate from each other. In the present study, we considered right and left sides separately.

The most common position of the MF on the right side was on the longitudinal axis of the second premolar (position IV) and on the left side it was on the longitudinal axis between the first and second premolars (position III). Our results are similar to the results presented in their studies by other authors (14-16), who also did a separate analysis of the right and left sides. Variability in MF position may be related to different feeding habits, subsequently affecting mandibular development (16). Prior knowledge of common positions in local populations may be helpful in effective nerve blocks and surgeries in those regions.

Knowledge of the average distance between the MF and the medial line and mental symphisis is important in clinical practice, because this foramen cannot be palpated or visualized, but its location is determined using the teeth (17). However, in cases of toothless mandibles, these values are used to locate the MF. In addition, other parameters may be used, such as the average distance between the foramen's lower edge on the mandible and the alveolar process or the angle of the mandible (17). All morphometric measurements in this paper are presented in the "Results" section and are similar to the results of previously conducted studies, but also within these studies racial and gender differences are registered. Many of the differences may be attributed to the nutrition habits of the population which affect the development of the mandible and the entire digestive system $(10,16,18)$.

We also measured the size of the MF. The mean vertical diameter (CD) of the MF in our study was $1.71 \mathrm{~mm} \pm 1.02 \mathrm{~mm}$ on the right side and $1.69 \mathrm{~mm} \pm 0.64 \mathrm{~mm}$ on the left side, respectively, and the mean horizontal diameter $(\mathrm{GH})$ was $2.56 \mathrm{~mm} \pm 1.05$ $\mathrm{mm}$ on the right side and $2.41 \mathrm{~mm} \pm 0.94$ $\mathrm{mm}$ on the left side, respectively. These results are very close to those of Igbigbi and Lebona (8). However, Oguz and Bozkir (19) did measurements in 34 dry mandibles of people from Turkey and found $3.14 \mathrm{~mm}$ on the left side, and a mean vertical diameter of $2.38 \mathrm{~mm}$ and $2.64 \mathrm{~mm}$ on the right and left sides, respectively. The present results differ significantly for HD from those of Oguz and Bozkir (19). In another study conducted by Singh and Srivastav (20), only the horizontal diameter was taken and the results showed the mean horizontal diameter to be 2.79 $\mathrm{mm}$ on the right side and $2.57 \mathrm{~mm}$ on the left side, again much less than in the present study. The probable reason for the significant difference in HD in their study was the higher number of round than oval MF.

In the present study, we observed an oval-shaped MF in $83.3 \%$ mandibles and a round-shaped MF in $16.7 \%$. The domination of the oval shape compared to the round shape was noted by other authors as well (21-23). The incidence of AMF varies in the literature. Singh and Srivastav (20) observed AMF in 13\% mandibles. Gershenson et al. (24) examined 525 dry mandibles and reported that $4.3 \%$ mandibles had a double MF and $0.7 \%$ mandibles had triple MF. However, Serman (25) reported the incidence of AMF to be $2.7 \%$. In the present study, we observed an AMF in 4/150 (2.7\%). An AMF is due to the branching of the mental nerve prior to its passing through the MF. Thus, the verification of the existence of an AMF would prevent nerve injury during periapical surgery.

\section{Conclusion}

Paralysis of the mental nerve is one of the principal complications of surgery of the mandibular canal and MF regions. There- 
fore, identification of the MF in its various positions and its morphometric analysis is important for dental surgeons in nerve block and surgical procedures, such as apical curettage of mandibular premolars and periodontal surgery, to avoid injury to the neurovascular bundle. In the majority of mandibles, we found an oval shaped foramina lying in position IV. However, variations exist in the position, shape, and size of the MF in different population groups. It is essential to be aware of the possibility of these anatomical variations while planning surgery in that region, to avoid nerve damage and also to enable effective mental nerve block anesthesia.

\section{What is already known on this topic}

- The position of the mental foramen has been reported to vary in different ethnic groups and in different historical populations.

- The location of the mental foramen is used in a number of maxillofacial surgical procedures and in anthropological examinations.

\section{What this study adds}

- This study has shown that this is the most common shape, position, number and size of MF in adult Bosnian mandibles, which may be useful and have future implications in our Bosnian population.

- The results of this research related to the position and direction of the mental foramen are similar to the results of research undertaken on the European population published so far.

Authors' contributions: Conception and design: AV, ET, AH; Acquisition, analysis and interpretation of data: AV; Drafting the article: AV, ET, AH; Revising it critically for important intellectual content: AV, ET, $\mathrm{AH}$.

Conflict of interest: The authors declare that they have no conflict of interest.

\section{References}

1. Lipski M, Tomaszewska IM, Lipska W, Lis GJ, Tomaszewski KA. The mandible and its foramen: anatomy, anthropology, embryology and resulting clinical implications. Folia Morphol (Wartsz). 2013;72(4):285-92.
2. Moiseiwitsch JR. Position of the mental foramen in a North American, white population. Oral Surg Oral Med Oral Pathol Oral Radiol Endod. 1998;85(4):457-60.

3. Ilayperma I, Nanayakkara G, Palahepitiya N. Morphometric analysis of mental foramen in adult Srilankan mandibles. Int J Morphol. 2009;27(4):1019-24.

4. Fabian FM. Position, shape and direction of opening of mental foramen in dry mandibles of Tanzanian adult black males. Ital J Anat Embryol. 2007;112(3):169-77.

5. Wismeijer D, van Waas MA, Vermeeren JI, Kalk W. Patients' perception of sensory disturbances of the mental nerve before and after implant surgery: a prospective study of 110 patients. Br J Oral Maxillofac Surg. 1997;35(4):254-9.

6. Greenstein G, Tarnow D. The mental foramen and nerve: clinical and anatomical factors related to dental implant placement-a literature review. J Periodontol. 2006;77(12):1933-43.

7. Tebo HG, Telford IR. An analysis of the variations in position of the mental foramen. Anat Rec. 1950;107:61-6.

8. Igbigbi PS, Lebona S. The position and dimensions of the mental foramen in adult Malawian mandibles. West Afr J Med. 2005;24(3):184-9.

9. Mbajiorgu EF, Mawera G, Asalann SA, Zivanovic S. Position of the mental foramen in adult Black Zimbabwean mandibles: a clinical anatomical study. Cent Afr J Med. 1998;44(2):24-30.

10. Santini A, Land MA. Comparison of the position of the mental foramen in Chinese and British mandibles. Acta Anat. 1990;137:208-12.

11. Green RM. The position of the mental foramen: a comparison between the southern (Hong Kong) Chinese and other ethnic and racial groups. Oral Surg Oral Med Oral Pathol Oral Radiol Endod. 1987;63(3):287-90.

12. Mwaniki DL, Hassanali J. The position of mandibular and mental foramina in Kenyan African mandibles. East Afr Med J. 1992;69(4):210-3.

13. Ngeow WC, Yuzawati Y. The location of the mental foramen in a selected Malay population. J Oral Sci. 2003;45(3):171-5.

14. Agarwal DR, Gupta SB. Morphometric analysis of mental foramen in human mandibles of south Gujarat. People’s J Sci Res. 2011;4(1):15-8.

15. Amorim MM, Prado FB, Borini CB, Bittar TO, Volpato MC, Groppo FC, et al. The mental foramen position in dentate and edentulous Brazilian's mandible. Int J Morphol. 2008;26(4):981-7.

16. Yesilyurt H, Aydinilioglu A, Kavakli A, Ekinci N, Eroglu C, Hacialiogullari M, et al. Local differ- 
ences in the position of the mental foramen. Folia Morphol. 2008;67(1):32-5.

17. Phillips JL, Weller RN, Kulild JC. The mental foramen: 1 . Size, orientation and positional relationship to the mandibular second premolar. J Endod. 1990;16(5):221-3.

18. Siddiqui AU, Daimi SR, Mishra PP, Doshi SS, Date JY, Khurana G. Morphological and morphometric analysis of mental foramen utilizing various assessment parameters in dry human mandibles. Int J Stud Res. 2011;1(1):19-22.

19. Oguz O, Bozkir MG. Evaluation of location of mandibular and mental for foramina in dry, young, adult human male, dentulous mandibles. West Indian Med J. 2002;51(1):14-6.

20. Singh R, Srivastav AK. Study of position, shape, size and incidence of mental foramen and AMF in Indian adult human skulls. Int J Morphol. 2010;28(4):1141-6.
21. Greenstein G, Tarnow D. The mental foramen and nerve: clinical and anatomical factors related to dental implant placement-a literature review. J Periodontol. 2006;77(12):1933-43.

22. Ilayperma I, Nanayakkara G, Palahepitiya N. Morphometric analysis of mental foramen in adult Srilankan mandibles. Int J Morphol. 2009;27(4):1019-24.

23. Fabian FM. Position, shape and direction of opening of mental foramen in dry mandibles of Tanzanian adult black males. Ital J Anat Embryol. 2007;112(3):169-77.

24. Gershenson A, Nathan H, Luchansky E Mental foramen and mental nerve: changes with age. Acta Anatomica. 1986;126(1):21-8.

25. Serman NJ. The mandibular incisive foramen. J Anat. 1989;167:195-8 